\title{
Proposing a Meta-Heuristic Algorithm for Enhanced Oil Recovery Using $\mathrm{CO}_{2}$ Injection
}

\author{
Mohammadi Raheleh'1, Hajnajafi Reza ${ }^{2}$ \\ ${ }^{1}$ Department of Chemistry, Tehran Centre branch of Islamic Azad University, Tehran, Iran \\ ${ }^{2}$ Department of Petroleum Engineering, University of New South Wales, Sydney, Australia \\ Email: raheleh.mohammadi22@gmail.com,rezahajnajafi@gmail.com
}

How to cite this paper: Raheleh, M. and Reza, H. (2016) Proposing a Meta-Heuristic Algorithm for Enhanced Oil Recovery Using $\mathrm{CO}_{2}$ Injection. Open Journal of Yangtze Gas and Oil, 1, 47-58. http://dx.doi.org/10.4236/ojogas.2016.13007

Received: August 9, 2016

Accepted: October 27, 2016

Published: October 30, 2016

Copyright () 2016 by authors and Scientific Research Publishing Inc. This work is licensed under the Creative Commons Attribution International License (CC BY 4.0).

http://creativecommons.org/licenses/by/4.0/

\begin{abstract}
With the increased global demand for crude oil, the increased reservoir lifetime, and the need for enhanced oil recovery methods, $\mathrm{CO}_{2}$ injection has become an efficient choice. This paper aimed to determine optimal $\mathrm{CO}_{2}$ injection choices using genetic algorithm, involving both optimized gas storage and enhanced oil recovery. There was no overlap between the objectives. Each was directly optimized and several optimal scenarios were developed at the same time. An advantage of this optimization method is that it is able to modify production scenario according to variations in optimization parameter values.
\end{abstract}

\section{Keywords}

Gas Injection, Gas Storage, Enhanced Oil Recovery, Genetic Optimization Algorithms

\section{Introduction}

Enhancing oil recovery by $\mathrm{CO}_{2}$ injection has recently attracted much attention [1] [2]. Since many flooding fields are close to the end of their life, $\mathrm{CO}_{2}$ injection has become an optimal choice. Gas or water drive methods usually leave 25\% $50 \%$ of oil in reservoirs [3]. A considerable portion of the remained oil can be recovered if oil contacts a miscible fluid. Such miscible fluid is formed through the combination of $\mathrm{CO}_{2}$ and oil under the desired conditions [4] [5]. Miscibility eliminates capillary pressure as the cause of oil immobilization, thereby enabling oil to move towards production wells. $\mathrm{CO}_{2}$ is injected in both miscible and immiscible ways. It is used for both tertiary recovery (oil recovery after water injection) and secondary recovery [6]. $\mathrm{CO}_{2}$ may be injected alone or in combination with hydrocarbon gases and azoth. While immiscible dissolved $\mathrm{CO}_{2}$ injection method has been used during the past years, miscible anhydride carbonic gas 
injection is now the top choice. Miscible $\mathrm{CO}_{2}$ injection is appropriate for light and medium oils, while immiscible injection is more suitable for heavy oils [7].

Environmental surveys suggest that $\mathrm{CO}_{2}$ constitutes around $64 \%$ of total greenhouse gases and is the main factor in the increased earth temperature and the changed weather conditions. The reduction of greenhouse gases in the atmosphere is a serious challenge in many industries such as oil and gas. Underground storage may be considered as an efficient technology for long-term storage of $\mathrm{CO}_{2}$ emitted from such resources as fossil power plants. A method for making storage process more economical is to link it to the enhanced hydrocarbon recovery operation in hydrocarbon reservoirs [8]. $\mathrm{CO}_{2}$ injection is an efficient method for enhanced oil recovery. While $\mathrm{CO}_{2}$ has been used for heavy oil production, it may also be efficient for light oil [9]. Trivedi et al. (2005) explored optimal conditions for $\mathrm{CO}_{2}$ storage in oil reservoirs using numerical modeling. In doing so, they studied the greenhouse gas sequestered during the enhanced tertiary oil recovery in western Texas using (CMG-GEM) simulator [10].

Babadagli (2006) investigated optimal conditions to achieve maximum oil production and $\mathrm{CO}_{2}$ storage using numerical modeling combined with a variety of injection methods such as miscibility and gas injection [11]. Oruganti (2010) studied underground $\mathrm{CO}_{2}$ storage and investigated pressure build-up risks [12]. Finally, Goreki et al. (2012) analyzed the feasibility of $\mathrm{CO}_{2}$ storage process in an oil reservoir [11] [13]. A global estimation suggests that 450 - 820 billion oil barrels and 130 - 240 gigatons of $\mathrm{CO}_{2}$ can be achieved by simultaneous enhanced oil recovery and $\mathrm{CO}_{2}$ storage process [14], the aim of the present study is to determine the optimal $\mathrm{CO}_{2}$ storage and enhanced oil recovery by using genetic algorithm.

\section{Proposed Method}

This study aimed to maximize $\mathrm{CO}_{2}$ storage and enhance oil production simultaneously using injection method. In doing so, we performed optimization process as follows. After developing reservoir model, we imaginarily demarcated the wells to prevent overlap between the affected areas. Next, we analyzed the sensitivity to determine the most influential parameters. We did so to determine the impact of objective function selection on parameters choice and to determine a suitable interval for parameter quantification during optimization process.

In single-objective approach, after determining the coefficients of storage and production functions according to decision maker, we selected an optimal scenario using genetic algorithm. In the developed approach as shown in multi-objective section, we determined the technical objective function while ignoring the coefficients of storage and production functions. Thereafter, we designed non-dominated ranking genetic algorithm as an optimization algorithm.

In this study, we analyzed the sensitivity to select optimal input parameters in multi-objective optimization process. In doing so, we employed D-Optimal test design method. Optimal design matrix consisted of $\mathrm{n}$ test and $\mathrm{X}$ 'X determinant value (X model coefficients function) was at its maximum amount. The number 
of executions covered the biggest possible region in the studied area [15] [16].

\subsection{Multi-Objective Optimization Process}

Reflection on most scientific decision problems suggests that multiple objectives or criteria are involved. In the past, the majority of multi-objective optimization problems used to be studied as a single-objective problem due to the lack of efficient solutions [17] [18]. However, it should be noted that fundamental differences exist in the nature of multi-objective and single-objective optimization algorithms. Solving multi-objective optimization problems by changing them into single-objective problems dates back to four decades ago. Since then on many algorithms have been proposed and many researchers have attempted to classify them based on various observations. In weighted sum model, user reduces multiple objectives into a single one by multiplying them by a proposed weight. With respect to multiple objectives, this method is the simplest solution which comes into mind. For example, where target function consists of function 1 (enhanced oil recovery) and function 2 (enhanced gas storage), the conventional method makes optimization by maximizing the weighted sum of the functions. While this is a simple idea, it provokes the question that what values the user should use for the weights. Obviously, there is no general answer to this question. The weight of an objective is typically selected according to relative importance of the objective in the problem. In most nonlinear optimization problems, a uniformly distributed collection of weight vectors does not necessarily lead to a uniformly distributed collection of Pareto optimal solutions. Since this mapping is typically unknown, it is difficult to achieve a Pareto optimal solution in a desired region of the objective space of weight vector. Also, different weight vectors do not necessarily lead to different Pareto optimal solutions. In nonlinear problems, it is unclear which weight vectors lead to an optimal solution [17] [18].

\subsection{Definition of Objective Function}

The majority of objective functions defined and used in separate and simultaneous investigations about enhanced oil recovery and $\mathrm{CO}_{2}$ storage processes are on single-objective basis. The general formula of these functions is as follows:

$$
\begin{aligned}
\text { Weigh } 3= & \text { Weigh } 1 \times \text { Enhanced Recovery Process } \\
& + \text { Weigh } 2 \times \mathrm{CO}_{2} \text { Storage Process }
\end{aligned}
$$

The majority of cases have a coefficient of 0.5. For instance, Cosk (2004) defined an objective function as a combination of oil recovery and $\mathrm{CO}_{2}$ storage. Jahangiri et al. (2010) proposed an objective function for simultaneous process of enhanced oil recovery and optimized gas storage. As with previous studies, they used the coefficient of 0.5 .

\subsection{Genetic Algorithm}

In this method, we first developed the primary population as usual based on problem scale and constraints and evaluated it from the viewpoint of the defined 
objective functions. Next, we performed non-dominated sorting. According to the definition, $A$ dominates $\mathrm{C}$ if it is not worse than $\mathrm{C}$ in any function and is better than it in at least one function. The population members were classified into several groups. The first group consisted of fully non-dominated members. The second group was dominated by the first group members, and this went on the same way in other groups. Every member in each group was allocated a rating according to group number. The aim of multi-objective optimization process was to find Pareto solutions (non-dominated) for the problem. Oil production and gas storage were two objectives in the multi-objective optimization process using non-dominated ranking genetic algorithm. We computed population distance parameter for each member in each group, which represented the distance of each sample to other members of the relevant group. Next, we selected parent population for reproduction and carried out mutation and intersection steps. Finally, we formed Pareto front, in which every answer was optimal [19] [20].

In this study, we utilized two optimization methods. The following represents single-objective and multi-objective optimization methods:

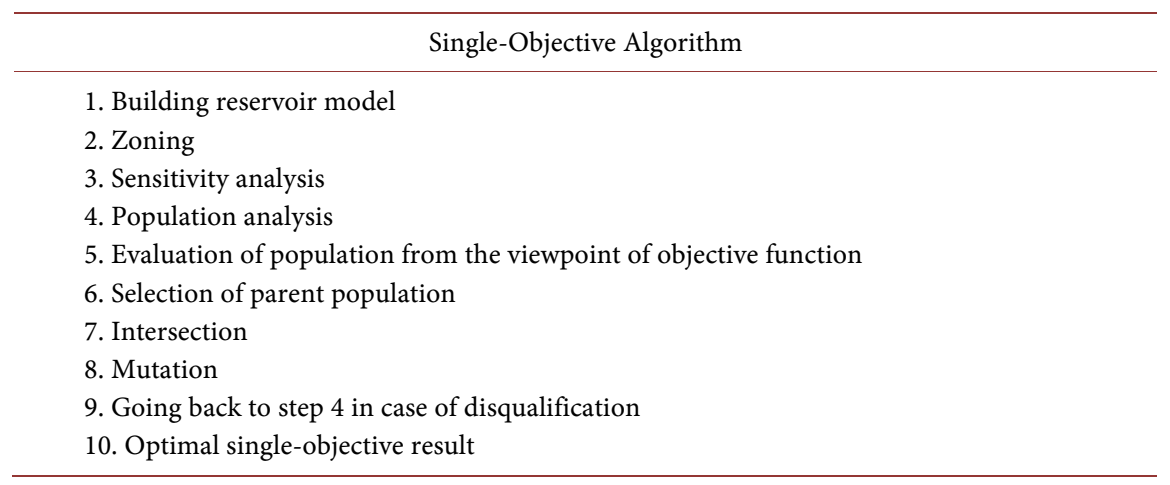

Multi-Objective Algorithm

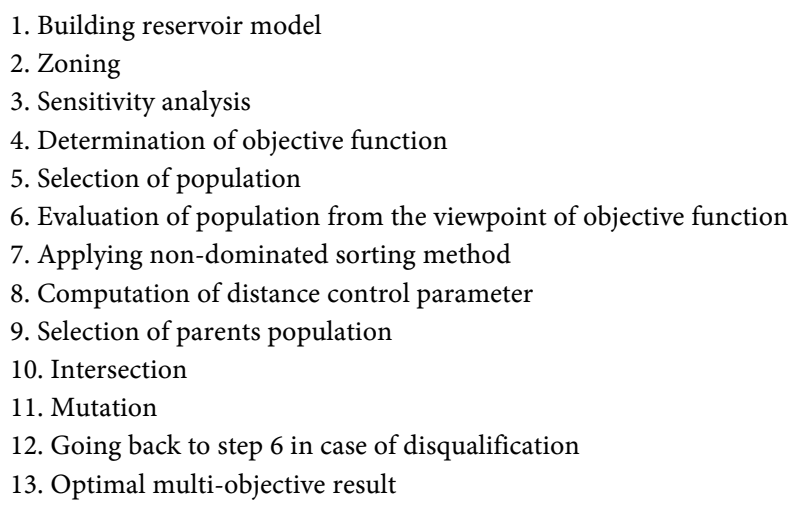

\subsection{Model Description}

In this study, we utilized a reservoir in Iran and simulated the model using a combined reservoir simulator (Eclipse-300). The model consisted of 4 production wells and 3 injection wells. The average reservoir depth and initial pressure were $11,000 \mathrm{ft}$ and 5620 psi respectively. The average horizontal permeability of 
the reservoir was $15 \mathrm{md}$ and its porosity was 0.09 . Horizontal-vertical permeability ratio was approximately 3 . The empty space volume was $10.5 \times 10^{10} \mathrm{ft}^{3}$, while initial oil phase saturation was 0.65 . The reservoir included $20 \times 20 \times 20$ grade blocks, out of which 3868 blocks were active. The average dimensions of each block in $\mathrm{X}, \mathrm{Y}$ and $\mathrm{Z}$ directions were 830,800 and $45 \mathrm{ft}$ respectively.

\section{Discussion}

\subsection{Optimization of Single-Objective Genetic Algorithm}

We analyzed the parameters using Design Expert. The required time for optimizing oil recovery and $\mathrm{CO}_{2}$ storage using single-objective genetic algorithm in continuous injection mode is 100 hours. The reservoir has been naturally exploited for 10 years. The injection scenarios have begun from the beginning of eleventh year and will be continued for twenty years. In the meantime, influential operating parameters are going to be optimized. The combination of objectives in single-objective genetic algorithm is essential.

Since the mean value of objective function variations was smaller than $10^{-6}$ in last generations, optimization stopped in $64^{\text {th }}$ generation. The corresponding control parameters are shown in Table 1. Injection wells 2 and 3 are approximately located in oil zone and injection well 1 is fully located in water zone. In the case of variation in parameter values, the entire optimization process has to be repeated.

\subsection{Optimization of Multi-Objective Genetic Algorithm}

In order to utilize non-dominated ranking multi-objective optimization method, we defined two objective functions for oil production value. We selected these objectives independent of theorem economy (technical function) and there was no need for scaling in contrast to single-objective method. The objectives were optimized independent of price fluctuations. In other words, the objectives were directly optimized in contrast to single-objective method where they are optimized indirectly (by help of net present value). The corresponding control parameters are shown in Tables 2-7. In this approach, the optimized gas injection

Table 1. Characteristics of single-objective and multi-objective genetic algorithm used for optimizing continuous $\mathrm{CO}_{2}$ injection process.

\begin{tabular}{ccc}
\hline Characteristic & Single-Objective & Multi-Objective \\
\hline Injection type & Continuous gas & Continuous gas \\
Number of generations & 500 & 500 \\
Number of population & 100 & 100 \\
Number of parameters & 50 & 50 \\
Pareto coefficient & & 0.5 \\
Crossover coefficient & 0.75 & 0.75 \\
Migration coefficient & 0.3 & 0.3 \\
Tolerance objection function & $10^{-6}$ & $10^{-4}$ \\
\hline
\end{tabular}


Table 2. Oil production rate.

\begin{tabular}{cccccc}
\hline Rate & Well Number & Single-Objective & \multicolumn{2}{c}{ Multi-Objective } \\
\hline & 4 & 9 & 10 & 7 & 7 \\
Oil production rate $\times 500(\mathrm{STB})$ & 3 & 10 & 14 & 13 & 11 \\
& 2 & 14 & 14 & 14 & 14 \\
& 1 & 14 & 12 & 12 & 13 \\
\hline
\end{tabular}

Table 3. Gas production rate.

\begin{tabular}{cccccc}
\hline Rate & Well number & Single-Objective & \multicolumn{2}{c}{ Multi-Objective } \\
\hline & 3 & 12 & 18 & 18 & 14 \\
Gas production rate $\times 1000(\mathrm{MSCF})$ & 2 & 17 & 18 & 18 & 17 \\
& 1 & 13 & 19 & 17 & 15 \\
\hline
\end{tabular}

Table 4. Oil production perforation length.

\begin{tabular}{cccccc}
\hline Rate & Well number & \multicolumn{2}{c}{ Single-Objective } & \multicolumn{2}{c}{ Multi-Objective } \\
\hline & 4 & 4 & 4 & 4 & 4 \\
Perforation length & 3 & 5 & 4 & 4 & 4 \\
& 2 & 3 & 4 & 4 & 4 \\
& 1 & 5 & 4 & 5 & 4
\end{tabular}

Table 5. Beginning of oil production perforation.

\begin{tabular}{cccccc}
\hline Rate & Well number & Single-Objective & Multi-Objective \\
\hline Beginning of perforation & 4 & 3 & 6 & 5 & 5 \\
& 3 & 7 & 3 & 2 & 5 \\
& 2 & 3 & 4 & 3 & 6 \\
\hline
\end{tabular}

Table 6. Beginning of injection well perforation.

\begin{tabular}{cccccc}
\hline Rate & Well number & Single-Objective & Multi-Objective \\
\hline Beginning of perforation & 3 & 7 & 4 & 3 & 3 \\
& 2 & 2 & 7 & 3 & 6 \\
\hline
\end{tabular}

Table 7. Injection wells situation.

\begin{tabular}{cccccc}
\hline Rate & Well number & Single-Objective & \multicolumn{2}{c}{ Multi-Objective } \\
\hline Injection wells situation & 3 & 39 & 40 & 33 & 26 \\
& 2 & 52 & 53 & 54 & 46 \\
\hline
\end{tabular}


scenarios were classified into three groups. The first group consisted of optimal solutions in terms of maximized gas storage (oil was also optimized as far as possible). The third group consisted of optimal solutions in terms of maximized oil production. The second group related to ideal solutions in terms of maximized objective without operating constraints. It should be noted here that all of these points are optimal from the viewpoint of multi-objective optimization process, but the distinguishing feature is the enhanced decision power under various operating conditions. The considerable point was the superiority of optimal solutions in the third group over single-objective optimization solutions. In the third group, oil production increased by $1,500,000$ barrels and $\mathrm{CO}_{2}$ storage increased by 32 billion $\mathrm{ft}^{3}$. These comparisons were made under equal conditions and without operating and economic constraints. Since multi-objective optimization method directly optimizes oil production and $\mathrm{CO}_{2}$ storage, one can investigate different economic scenarios and select the best mode from among the existing solutions in each scenario. In practice, single-objective method is unable to achieve optimal solutions obtained from multi-objective optimization method. The first reason is that single-objective optimization method has to be executed for different weights, which would be costly and time-consuming in practice. In multi-objective optimization method, the required time for achieving Pareto optimal solutions is 114 hours. The same takes around 1500 hours in single-objective method with the assumption that the weight of each function is known. The second reason is that the weights leading to optimal solutions are unknown.

In order to determine the impact of continuous injection scenario on oil recovery, we first optimized the model on single-objective and multi-objective bases. Figure 1 and Figure 2 illustrate the results.

In this study, we prepared seven samples of Iranian oil reservoirs using $\mathrm{CO}_{2}$ injection method. Then we computed production rates of both recovery enhancement methods, involving six parameters of porosity, permeability, gravity,

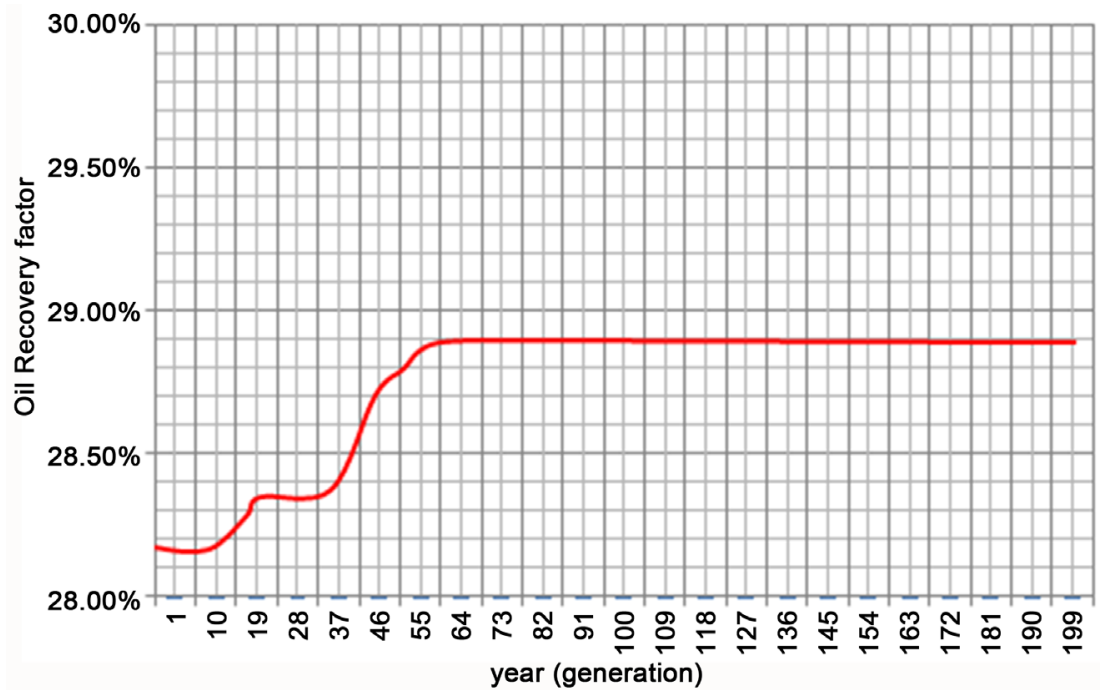

Figure 1. Improvement in single-objective method in 200 generations. 


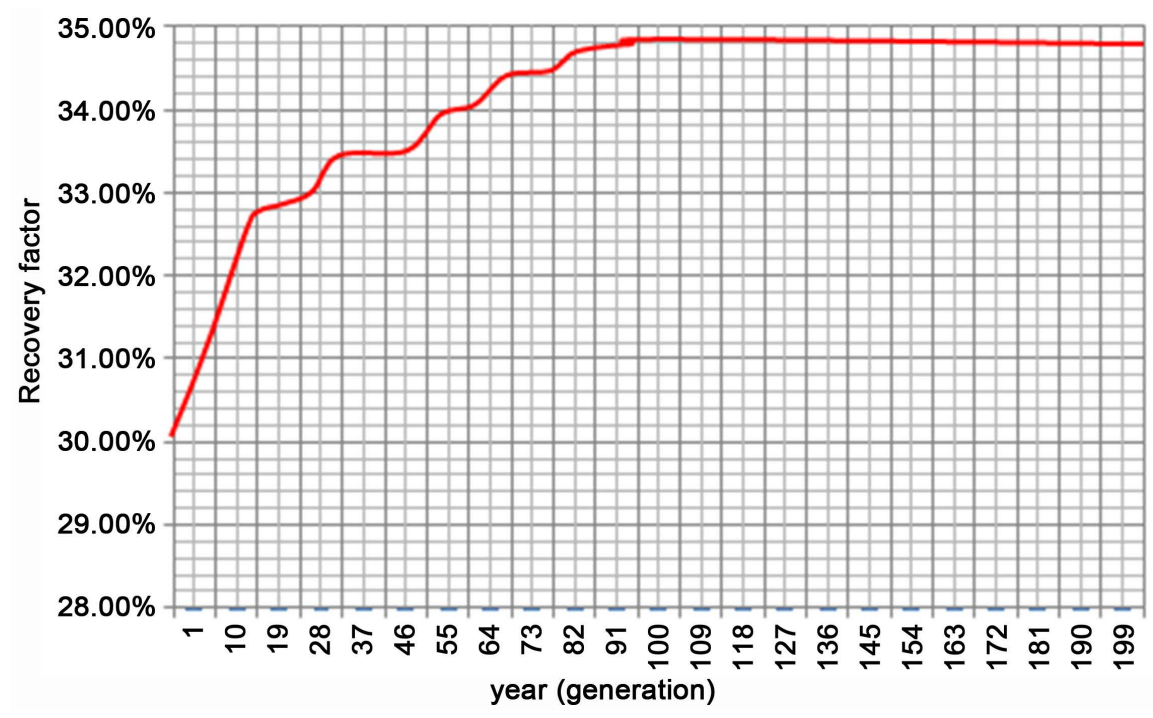

Figure 2. Improvement in multi-objective method in 200 generations.

viscosity, temperature and depth. Production rate is obtained from dividing the volume produced under direct influence of recovery enhancement process by total oil production volume (natural production + production obtained from enhanced recovery). This ratio represents the effectiveness of algorithm in the enhanced oil recovery process. We first had to develop a model with the ability to perceive the impact of reservoir parameters on oil production rate obtained from recovery enhancement methods. Then we selected six parameters as network input, with the output being the production rate obtained from recovery enhancement methods. Table 8 summarizes some of these samples and Figure 3 shows the effectiveness of the algorithm.

After studying the simulation results, we inputted the data of seven oil reservoirs located in southwest of Iran into the algorithm and estimated recovery enhancement share of each. Table 9 summarizes the statistical data of input parameters together with estimated recovery enhancement shares and Figure 4 illustrates the algorithm effectiveness on each reservoirs.

Figure 5 compares the data before and after the algorithm. As you can see, the algorithm is able to precisely predict the production rate obtained from recovery enhancement method. Thus, the proposed algorithm achieves the goal by finding recovery enhancement shares in which error function reaches its minimum.

\section{Conclusions}

- Multi-objective optimization method, combined with non-dominated sorting genetic algorithm, enhanced decision power under various economic conditions such as $\mathrm{CO}_{2}$ emission tax fluctuations. Storage becomes more important as $\mathrm{CO}_{2}$ emission tax increases.

- Multi-objective optimization method is more efficient than single-objective method. On this basis, oil production increased by $1,500,000$ barrels and $\mathrm{CO}_{2}$ storage increased by 32 billion $\mathrm{ft}^{3}$ in the third group. 


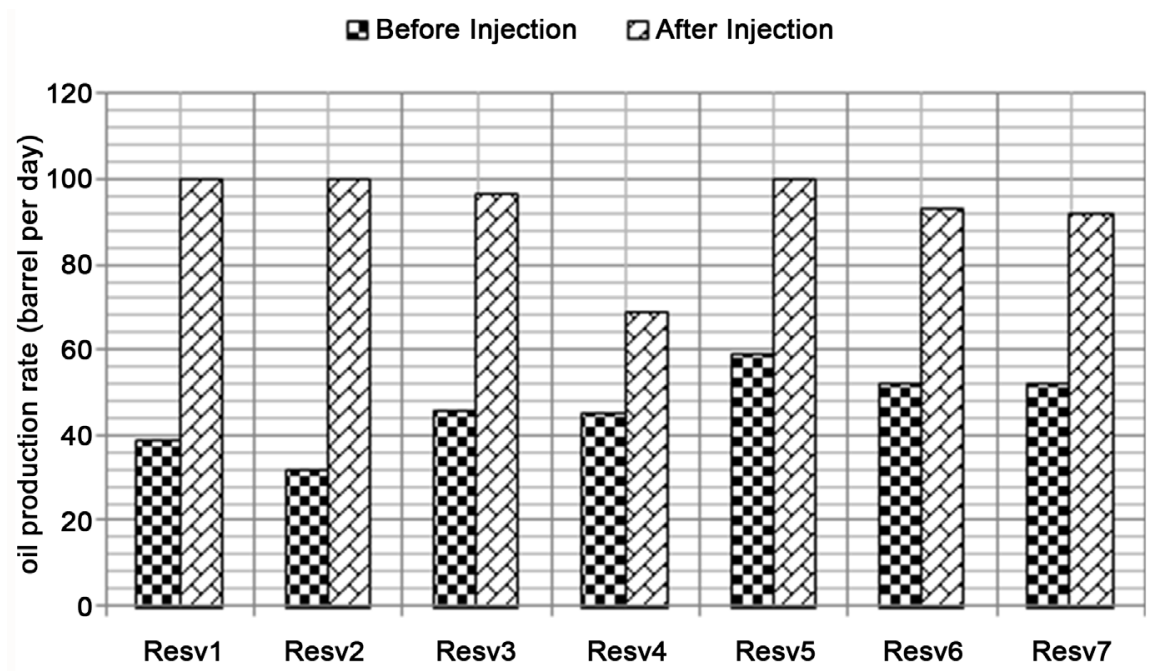

Figure 3. Improvement of seven simulated reservoirs.

Table 8. Parameters of seven simulated reservoirs.

\begin{tabular}{lcccccc}
\hline Reservoir & Permeability & $\begin{array}{c}\text { Porosity } \\
(\%)\end{array}$ & $\begin{array}{c}\text { Gravity } \\
\text { (API) }\end{array}$ & $\begin{array}{c}\text { Viscosity } \\
\text { (cp) }\end{array}$ & Depth (ft) & $\begin{array}{c}\text { Temperature } \\
\text { (F) }\end{array}$ \\
\hline Reservoir 1 & 75 & 18 & 37 & 0.6 & 1900 & 105 \\
Reservoir 2 & 30 & 17 & 35 & 0.6 & 1600 & 99 \\
Reservoir 3 & 6 & 12.5 & 32 & 1 & 4900 & 110 \\
Reservoir 4 & 3 & 10 & 32 & 2 & 5000 & 107 \\
Reservoir 5 & 70 & 16 & 30 & 3 & 6200 & 115 \\
Reservoir 6 & 63 & 15 & 38.5 & 2 & 7260 & 152 \\
Reservoir 7 & 63 & 15.2 & 38 & 2 & 7300 & 152 \\
\hline
\end{tabular}

Table 9. Data of seven reservoirs located in the southwest of Iran.

\begin{tabular}{lcccccc}
\hline Reservoir & Permeability & $\begin{array}{c}\text { Porosity } \\
(\%)\end{array}$ & $\begin{array}{c}\text { Gravity } \\
(\text { API })\end{array}$ & $\begin{array}{c}\text { Viscosity } \\
(\mathrm{cp})\end{array}$ & $\begin{array}{c}\text { Depth } \\
(\mathrm{ft})\end{array}$ & $\begin{array}{c}\text { Temperature } \\
(\mathrm{F})\end{array}$ \\
\hline Reservoir 1 & 14.7 & 11.5 & 34 & 0.666 & 3700 & 181 \\
Reservoir 2 & 1.45 & 5 & 34 & 1.3 & 6000 & 181 \\
Reservoir 3 & 1.6 & 7.1 & 16.6 & 4.16 & 14,642 & 278 \\
Reservoir 4 & 1.6 & 7.2 & 33.95 & 3.12 & 2280 & 128 \\
Reservoir 5 & 7.48 & 9 & 30 & 1.3 & 500 & 171 \\
Reservoir 6 & 0.672 & 5 & 30.2 & 1.31 & 3900 & 171 \\
Reservoir 7 & 19.93 & 14.5 & 27.6 & 1.3 & 5528 & 177 \\
\hline
\end{tabular}

- Given that oil recovery has increased by $18 \%, \mathrm{CO}_{2}$ injection method may considerably enhance oil recovery. 


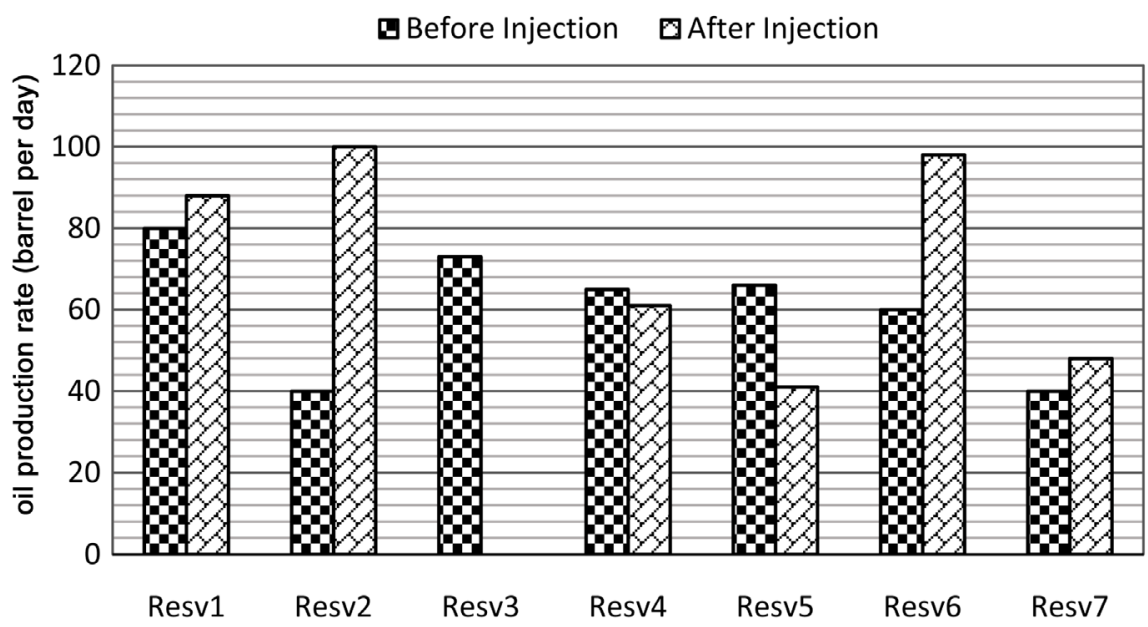

Figure 4. Improvement of seven reservoirs located in southwest of Iran.

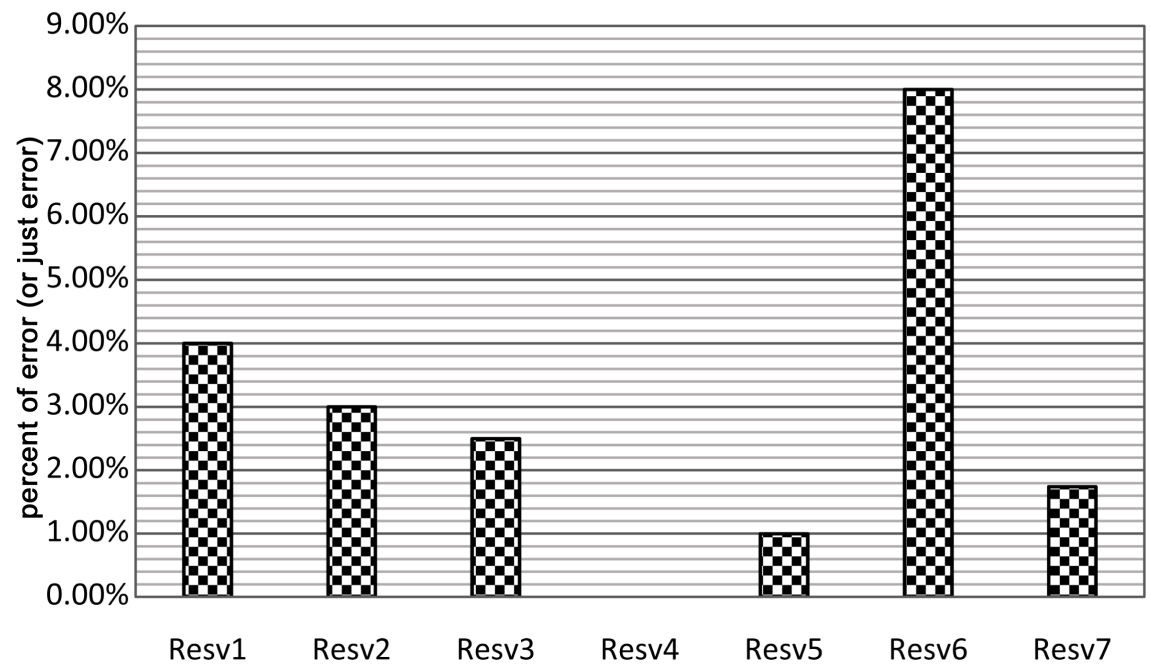

Figure 5. Percentage of error in estimation of the enhanced recovery.

- Multi-objective optimization method offers shorter optimization time than single-objective method does. As the result, it offers faster decision-making.

\section{References}

[1] Reza, H., Arman, A. and Ghazal, H. (2016) Comparative Study on Oil Recovery Enhancement by WAG Injection Technique in a Fractured Oil Reservoir in the Southwest of Iran. Journal of Petroleum \& Environmental Biotechnology, 7, 263.

[2] Alkhatib, A. and King, P. (2014) Uncertainty Quantification of a Chemically Enhanced Oil Recovery Process: Applying the Probabilistic Collocation Method to a Surfactant-Polymer Flood. Computers \& Geosciences, 18, 77-101. https://doi.org/10.1007/s10596-013-9384-9

[3] Perez Rodriguez, S., Soto, B.R. and Soto, D. (2013) The Development of a New Methodology to Reduce Uncertainty in Implementing a New EOR Project. International Petroleum Technology Conference, 26 March 2013.

[4] Saleh, L.D., Wei, M. and Bai, B. (2014) Data Analysis and Novel Screening Criteria for Polymer Flooding Based on a Comprehensive Database. SPE169093MS, SPE Reservoir Evaluation \& Engineering, 17, 15-25. https://doi.org/10.2118/168220-PA 
[5] Jelic, V., de Bruyn, A.G., Mevius, M., Abdalla, F.B., Asad, K.M.B., Bernardi, G., Brentjens, M.A., Bus, S., Chapman, E., Ciardi, B., Daiboo, S., Fernandez, E.R., Ghosh, A., Harker, G., Jensen, H., Kazemi, S., Koopmans, L.V.E., Labropoulos, P., Bentum, M.J., Best, P., Falcke, H., et al. (2014) Initial LOFAR Observations of Epoch of Reionization Windows: Diffuse Polarized Emission in the ELAIS-N1 Field. Astronomy \& Astrophysics, 568, 1-12.

[6] Switzer, E.R. and Liu, A. (2014) Erasing the Variable: Empirical Foreground Discovery for Global $21 \mathrm{~cm}$ Spectrum Experiments. The Astrophysical Journal. arXiv:1404.7561.

[7] Christman, P.C. and Gorell, S.B. (1988) A Comparison of Laboratory and FieldObserved $\mathrm{CO}_{2}$ Tertiary Injectivity. SPE/DOE Enhanced Oil Recovery Symposium, Tulsa, 17-20 April 1988, Article No. 17335.

[8] Babadagli, T. (2006) Optimization of $\mathrm{CO}_{2}$ Injection for Sequestration/Enhanced Oil Recovery and Current Status in Canada. In: Lombardi, S., Altunina, L.K. and Beaubien, S.E., Eds., Advances in the Geological Storage of Carbon Dioxide, Springer, Houten, 261-270.

[9] Rahman, S., Nofel, W., Al-Majed, A., Arshad, A. and Menouar, H. (2010) Phase Behavior Aspects of Carbon Dioxide (COR2R) Miscible Flooding in Tight Cores: A Case Study. SPE 128467.

[10] Trivedi, J.J. and Babadagli, T. (2005) CO and Flue Gas Sequestration during Tertiary Oil Recovery: Optimal Injection Strategies and Importance of Operational Parameters. Canadian International Petroleum Conference, Calgary, Alberta, 7-9 June 2005.

[11] Hamling, G.J.A., Klapperich, R.J., Steadman, E.D.N. and Harju, J.A. (2012) Energy \& Environmental Research Integrating $\mathrm{CO}_{2} \mathrm{EOR}$ and $\mathrm{CO}_{2}$ Storage in the Bell Creek Oil Field. Carbon Management Technology Conference, Orlando, 7-9 February 2012. https://doi.org/10.7122/151476-MS

[12] Oruganti, Y.D. (2010) Geologic COR2R Storage: Understanding Pressure Perturbations and Estimating Risk Due to Pressure Buildup. The Faculty of the Graduate School of the University of Texas at Austin in Partial Fulfillment of the Requirements for the Degree of Master of Science in Engineering.

[13] Samira, A.D., Mohammad, T., Mehdi, A.S. and Hamid, G. (2012) Designing Multi-Objective Optimization Algorithm Combined with Biogeography Algorithm and Differential Evolutionary Algorithm. Intelligent Systems in Electrical Engineering, 3, 11-23.

[14] Wilkinson, J.R., Leahy-Dios, A., Teletzke, G.F. and Dickson, J.L. (2010) Use of COR2R Containing Impurities for Miscible Enhanced Oil Recovery. SPE 131003.

[15] Triefenbach, F. (2008) Design of Experiments: The D-Optimal Approach an Implementation as a Computer Algorithm. South Westphalia University of Applied Sciences, Iserlohn.

[16] Lawal, A.A. (2007) Applications of Sensitivity Analysis in Petroleum Engineering. The University of Texas, Austin.

[17] Konaka, A., Coit, D.W. and Smith, A.E. (2006) Multi-Objective Optimization Using Genetic Algorithms: A Tutorial. Reliability Engineering and System Safety, 91, 9921007. https://doi.org/10.1016/j.ress.2005.11.018

[18] Sbalzariniy, I.F., Ullery, S.M. and Koumoutsakosyz, P. (2000) Multi-Objective Optimization Using Evolutionary Algorithms. Center for Turbulence Research.

[19] Marler, R.T. and Arora, J.S. (2004) Survey of Multi-Objective Optimization Methods for Engineering. Structural and Multidisciplinary Optimization, 26, 369-395. https://doi.org/10.1007/s00158-003-0368-6 
[20] Xie, Q., Li, S. and Yang, G. (2005) Studies on Fast Pareto Genetic Algorithm Based on Fast Fitness Identification and External Population Updating Scheme. Chinese Academy of Science, Beijing.

Submit or recommend next manuscript to SCIRP and we will provide best service for you:

Accepting pre-submission inquiries through Email, Facebook, LinkedIn, Twitter, etc. A wide selection of journals (inclusive of 9 subjects, more than 200 journals)

Providing 24-hour high-quality service

User-friendly online submission system

Fair and swift peer-review system

Efficient typesetting and proofreading procedure

Display of the result of downloads and visits, as well as the number of cited articles

Maximum dissemination of your research work

Submit your manuscript at: http://papersubmission.scirp.org/

Or contact ojogas@scirp.org 